\title{
Medial Pedicle Reduction Mammoplasty in Macromastia
}

\author{
Hany Salah, Mostafa Bayoumi, Ayman M. Abdelmufeed, Mohamed Y. Farid
}

\begin{abstract}
Department of General Surgery, Faculty of Medicine, Benha University, Egypt.

Correspondence to:

Mohamed Y. Farid,

Department of General Surgery, Faculty of Medicine Benha University, Egypt.
\end{abstract}

Email:

drmohamedyehia2016@gmail.com

Received: 23 September 2019

Accepted: 15 November 2021

Background: This study is going to evaluate the benefit and low morbidity rate of medial pedicle reduction mammoplasty on improving symptoms of macromastia with preservation of nipple and areola and avoiding depigmentation and hyperpigmentation of nipple and areola, preservation of lactation and about contour of the breast. Objective: This study aim to evaluate the benefit and low morbidity rate of medial pedicle reduction mammoplasty on improving symptoms of macromastia with preservation of nipple and areola and avoiding depigmentation and hyperpigmentation of nipple and areola, preservation of lactation and about contour of the breast. Patient and Methods: This is a clinical study including twenty female patients all had the problem of macromastia and all have undergone medial pedicle reduction mammoplasty at Benha university. Their mean age was 31years (25-45 years). All patients were evaluated preoperative and postoperative with mean follow up to 6months. Results: Clinical outcome measures significantly improved after surgery. Preoperatively there were 20 patients suffering from macromastia. Postoperatively they were all satisfied with the results with only 2 patients suffered from complications 1 with wound dehiscence and 1 with nipple and areola necrosis. 4 patients had secondary surgery 2 of them had liposuction of lateral bulge, 1 patients had revision of scar and 1 patient had excision of dog ear. Conclusion:This study demonstrates that medial pedicle reduction mammoplasty is a safe surgical option for severe mammary hypertrophy. Current options include amputation mammoplasty with freenipple graft and the inferior pedicle and bipedicle techniques.

Keywords: mammary hypertrophy - macromastia - medial pedicle reduction 


\section{Introduction}

Macromastia is defined as excessive size of the mammary glands.. The condition macromastia has not been defined and characterized precisely by the medical community. Whether the patient with hypertrophic breasts is a candidate for or can be helped by reduction mammoplasty is unclear to both the medical and the lay community [1].

Patients rated the severity of their somatic pain symptoms and discomfort before reduction mammoplasty and again after complete recovery. The severity of their symptoms and complaints was numerically graded and analyzed. Headache, neck pain, back pain, shoulder pain, and bra strap groove pain were present in 60 to 92 percent of patients, and 97 percent of patients had at least three of these pain symptoms preoperatively. All the patients after medial pedicle reduction mammoplasty had reduction of their pain symptomatology postoperatively, and 25 percent of the study patients had total elimination of pain symptoms.

Current options in reduction mammoplasty for severe mammary hypertrophy include amputation with free-nipple graft as well as the inferior pedicle and bipedicle techniques.
Complications of these procedures include nipple-areola necrosis, insensitivity, and hypopigmentation. The purpose of this study was to determine whether medial pedicle reduction mammoplasty can minimize these complications. Twenty-three patients with severe mammary hypertrophy were studied. The medial pedicle successfully transposed the nipple-areola complex in 44 of 45 breasts (98 percent). Mean change in nipple position was $17.1 \mathrm{~cm}$, and mean weight of tissue removed was $1604 \mathrm{~g}$ per breast. Nipple-areola sensation was retained in 43 of 44 breasts (98 percent) using a medial pedicle. Hypopigmentation was not observed, and central breast projection was restored in all patients. This study has demonstrated that medial pedicle reduction mammoplasty is a safe and reliable technique and should be given primary consideration in cases of severe mammary hypertrophy [2].

Management of severe mammary hypertrophy continues to be optimized. Common surgical options for reduction mammoplasty include amputation with freenipple graft as well as the bipedicle and inferior pedicle techniques. All three methods are used extensively; however, there are disadvantages to each when used 
for severe mammary hypertrophy. Disadvantages include reduced nipple sensation, nipple-areola necrosis, hypopigmentation, and poor breast projection.1-3 This study describes a new technique of reduction mammoplasty using a medially based dermal pedicle for nippleareola transposition that effectively eliminates these complications.

Definitions of severe mammary hypertrophy are varied and include cup size, weight of resected breast tissue, and height of nipple elevation.9-11 Inclusions for this study required a minimum distance from the nipple to the inframammary fold of $16 \mathrm{~cm}$ [3].

\section{Patients and methods}

This prospective study was approved by ethical committee of Faculty of Medicine Benha university and a written consent was taken from patients and conducted at Benha university hospital during the period between December 2017 and December 2018. This is a clinical study including twenty female patients all had the problem of macromastia and all have undergone medial pedicle reduction mammoplasty.

- Inclusion criteria: Female gender, variable age groups from $25-45$ years,
Variable marital and maternal status \& requesting breast reduction.

- Exclusion criteria: Chronic heavy smokers, major uncontrolled medical illness, ongoing medications interfering with coagulation mechanism \& significant breast lumps detected clinically or radiological.

Patients followed up for a period of 6 months at least.

\section{Preoperative Assessment:}

1. Patient age and whether a teen age, woman in child bearing period or postmenopausal.

2. Patient marital status and parity.

3. Height and weight.

4. Thorough history with stress on main complaint physical and family history of breast cancer.

5. Breast examination: Breast examination has been performed while the patient was sitting, upright, leaning forward and lying supine.

Apart from standard breast examinations certain points have been stressed on:

a. Degree of hypertrophy: As included roughly by the cup size that fits the breast: 
i. Mild hypertrophy with cup size B. ii. Moderate hypertrophy with cup size C. iii. Major hypertrophy with cup size D.

b. Degree of ptosis: As defined by relation between the level of the nipple and IMF. It's:

i. Minor if it's at or just below IMF. ii. Moderate if it's within $3 \mathrm{~cm}$ below IMF. iii. Severe if it's more than $3 \mathrm{~cm}$ below IMF.

c, Linear measurements of both breasts: nipple to sternal notch, nipple to IMF, and inter nipple distances are the most crucial.

d. Sensation in nipple and areola : for both crude and fine touch.

e. Symmetry of both breasts.

f- Skin quantity (excess): minimal, moderate or massive.[4].

g, Skin quality (elasticity): normal or inelastic. as tested by stria, skin thickness and skin recoil [4].

h, Skin/parenchyma relationship: firmly adherent or loosely adherent [4].
6. Routine investigations including full blood picture, liver function tests, fasting blood sugar.

7. Preoperative mammogram for high risk patients and those older than 35 years [5].

8. The location and length of the possible scars were shown and described to the patients, whom desire influenced the choice of the technique.

9. Preoperative views of photos should be taken and reviewed with the patient to point out conditions such as pre-existing asymmetry. Representative before and after photos also should be reviewed to insure that the patient understands the scars and has realistic expectations.

10. Any intertrigo is treated with topical antifungal and patient should be free from the disease at least one week prior to the operation.

11. The patient is asked to bath the night of the operation.

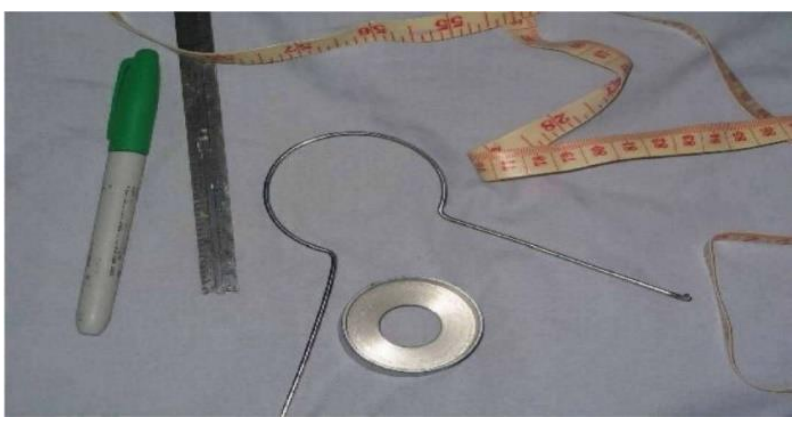

Fig. (1): Some tools used in marking 


\section{Il. Operative Procedure}

For all patients reduction mammoplasty was done using the medial pedicle technique was done under G. A with prophylactic antibiotics. All tissues removed were weighed then sent for histopathological assessment.

\section{Markings and technique}

\section{Marking}

In the operating room with the patient supine, the areolar diameter is marked at 4.2 $\mathrm{cm}$. the medial pedicle is defined with the base of the pedicle oriented medially, such that one-third of the total base width is along the medial vertical limb and two-thirds of the width is along the medial horizontal limb mean base width of the medial pedicle was $9.4 \mathrm{~cm}$. (range, 6 to $\mathrm{I} \mathrm{lcm}$ ), and mean distance from the base to nipple was 14.8 $\mathrm{cm}$ (range, 10 to $19 \mathrm{~cm}$ ). The distal aspect of the medial pedicle is delineated with a $\mathrm{I}-\mathrm{cm}$ margin around the nipple-areola complex to preserve the vascular plexus.

\section{Technique}

Local vasoconstriction is obtained by first infiltrating lidocaine with epinephrine along the proposed incisions (excluding the base of the medial pedicle). The medial pedicle is deepithelialized, leaving the nipple-areola complex intact dermoglandular wedge excisions of the medial, inferior, lateral, and superolateral portions are performed. The attachments of the medial pedicle to the chest wall are maintained. Excising the lateral aspects of the pedicle facilitates pedicle rotation and positioning. The presence of bleeding is assessed at the distal aspect of the pedicle. Absence of bleeding necessitates conversion to free-nipple graft. A temporary trifurcation suture is placed approximating the inferior corner of the medial and lateral vertical limbs of the wise pattern to a predetermined point on the inferior horizontal limb of the wise pattern the nipple-areola complex is rotated superiorly toward the apex of the vertical limbs. Twisting or kinking of the pedicle is avoided.

The skin edges are stapled temporarily, and the patient is positioned upright to assess breast symmetry, fullness, and nipple position. The nipple-areola complex is exteriorized with its base at $4.5 \mathrm{~cm}$ above the inframammary fold. A single drain is placed, and the incisions are closed with interrupted dermal and continuous subcuticular sutures. 

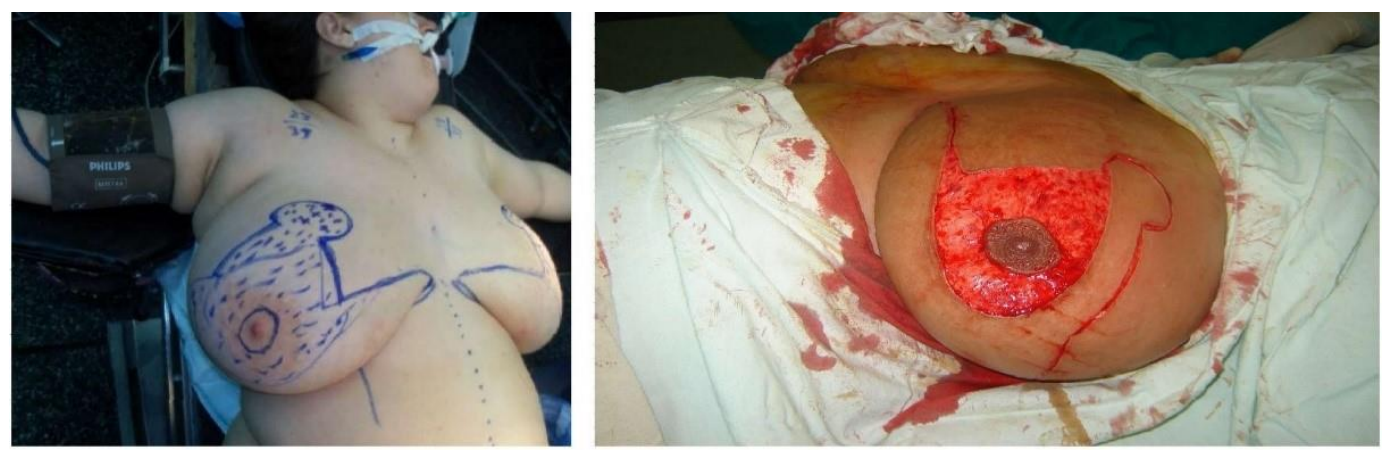

Fig. (2 a,b): Markings of medial pedicle

\section{Ill. Postoperative Management}

Suction drains were removed when amount is less than $20 \mathrm{~cm}$.

A light dressing was used to cover the wounds with the use of Vaseline gauze to cover the areolae and nipples. The viability of the areolae and nipples were checked the night of the operation.

The dressing was changed the next day and the wound was checked for hematoma or undue tension and the viability of the areola and nipples were again checked.

The dressing was changed every third day or when there was any soaking or suspicion of infection.

The patients were encouraged to go out of bed the next day to prevent DVT. For the morbidly obese patient's heparin 5000 units subcutaneously every 12 hours were started 2 hours before surgery and continued thereafter until out of bed activity was achieved by the patient.
The patient were a well-fitting bra the next day and continuously for the following postoperative month.

Prophylactic antibiotics were administered for 48 hours postoperatively and stopped thereafter.

'Narcotics achieved proper analgesia in the immediate postoperative period and thereafter by a non-steroid antiinflammatory analgesic medication. The peri-areolar sutures and the sutures in the inframammary fold were removed after ten days and the vertical sutures after 14 days.

\section{Medial pedicle techniques}

Understanding the anatomy is essential to understanding how to design pedicles and flaps. There is a superficial and a deep blood supply to the breast. The deep vessels come from the internal mammary system and perforate the pectoralis muscle usually just above the fifth rib (about 4-6 $\mathrm{cm}$ above the inframammary fold) and just medial to 
breast meridian. There are branches from this system which extend laterally in the septum described by Elisabeth wuringer." The arteries are accompanied by venae comitantes. The deep system supplies an Inferior and central pedicle. The superficial system has been documented by Ian Taylor" and the arteries and veins have been pushed into the superficial fatty layer as the breast enlarges. The arteries and veins travel separately and the veins are quite superficial and can be seen through the skin. They drain superiorly and medially which means that superior and medial pedicles are well supplied. The superomedial pedicle is robust and supplied by a large descending artery from the second or third interspace from the internal mammary system. This artery can be easily identified with a Doppler and it is about one centimeter deep to the skin surface and usually just medial to breast meridian. A truly medial pedicle will miss incorporating this artery but it is supplied by other medial vessels from the internal mammary system. A medial pedicle is safe as long as it is not excessively long and not undermined close to the sternum. The arteries are superficial over the breast tissuebut they come from deeper around the breast periphery. The medial vessels come from around the lateral border of the sternum. There are several nerves that 1025 supply sensation to the nipple and areola. The lateral branch of the fourth intercostal nerve is the main nerve but there are also medial nerves and some from the superior thoracoacromial system. The lateral branch of the fourth intercostal nerve has one branch that runs above the breast tissue toward the areola and a deep branch which runs along the pectoralis muscle and then runs vertical toward the areola at the breast meridian. This deep and superficial system is similar to the vascular supply. Maintaining, full thickness supero-medial pedicle will the deep branch of the nerve although the superficial lateral branch will be sacrificed. Superior and medial nerve branches will also be preserved. About $85 \%$ of patients with the supero-medial pedicle will recover normal to near-normal sensation.

\section{The medial pedicle techniques include the}

\section{2 famous techniques:}
A) The Superior Medial Pedicle Technique.
B) The medial pedicle technique.

\section{A) The Superior Medial Pedicle Technique}

The supero-medial pedicle technique is a safe and reliable procedure in patients with severe gigantomastia and its versatility allows to be performed on all types of 
breasts regardless of size or degree of ptosis. The superior medial pedicle technique is a variant of the superior central pedicle technique. [6] have first published this technique. Later Hauben (1985)[7] and Finger and associates (1989)[8] popularized it.

This technique IS reserved for patients who have good breast microcirculation. It is better not to be used-for women post menopause, cigarette smokers and those with other signs of impaired microcirculation. It is selected when the nipple-complex elevation is restricted because of firm dense breast parenchyma or when the nipple- areola complex needs be moved a greater distance upward than is possible with the superior central pedicle technique. This technique is done exactly like the superior central pedicle technique with the difference only being in the site of the pedicle bearing the nipple areola complex. Here the pedicle is left superomedially where a full-thickness cut is made through the breast parenchyma laterally within the $\mathrm{V}$ from the inframammary crease area up to the future nipple-areola site. A small back-cut of about I to $2 \mathrm{~cm}$ may be needed along the medial border of the $\mathrm{V}$ to facilitate the mobility of the nipple-areola complex. The nippleareola and the superior medial pedicle are then rotated upward and laterally until the nipple-areola complex is at the proposed site. To facilitate pedicle transposition, some of the medial dermis but not the subdermal vessels can also be incised. The rotation is easier when the pedicle is longer and the breast is larger because the length of the pedicle increases. The lateral to medial closure fills the deficit from the upward pedicle transposition [9]. There are many advantages of the superior medial pedicle technique of reduction mammoplasty. The thick pedicle is responsible for the projection of the apex of the new breast cone. Also the thick pedicle provides a better bulk for the nipple-areola complex. It prevents nipple retraction and inversion due to the lack of bulk support deep to the nipple [10].

-Lateral incision for parenchymal pedicle -Superior medial pedicle Lower resection 


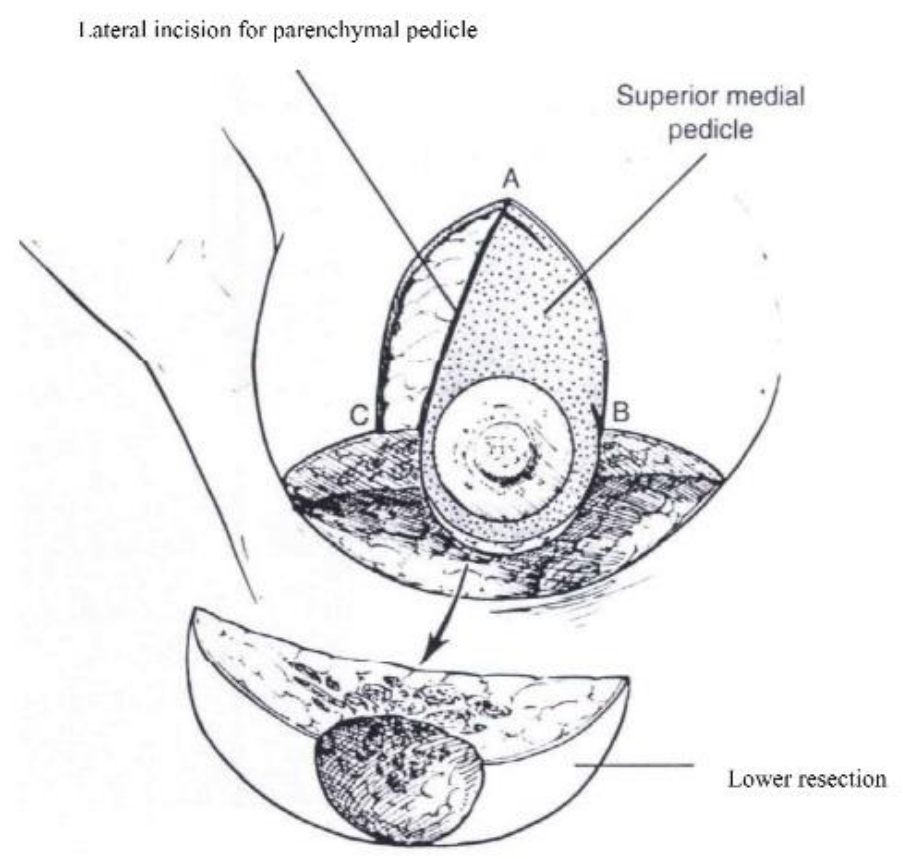

Fig. (3): The superior medial pedicle technique [9]

The superior medial pedicle permits a safe lateral resection and if necessary a more aggressive reduction of the lateral breast pole that is usually carrying most of the breast fullness in cases of hypertrophy. The superior medial pedicle serves to fill, well the medial quadrant of the breast, which offers a more natural and pleasing appearance. Moreover, the medial part of the flap may partially prevent superior migration of the complex at a later date [7]. In addition the medial aspect of the dermal pedicle carries fibers from the anterior cutaneous branches of the fourth and fifth intercostal nerves to guarantee sensibility. Also, the preservation of this thick broadbased pedicle ensures better viability [6].
(Finger et ale 1989)[8], described using superomedial pedicle for resection as large as $4100 \mathrm{gm}$. and NAC transposition up to 30 $\mathrm{cm}$ with reliable NAC survival and preservation of sensation.

\section{B) The medial pedicle technique:}

The principle of the medial pedicle is derived from the superomedial technique of reduction mammoplasty described by [11]. The superomedial pedicle was designed to shorten pedicle length and broaden pedicle width as a means of enhancing blood flow and maintaining innervation to the nippleareola complex. Numerous studies revealed that pedicle is effective in the management of mild to moderate mammary hypertrophy, 
however, it has not been used for severe mammary hypertrophy. Possible reasons include excessive pedicle length as well as torsion, twisting, and compression of the pedicle because of its limited are of rotation. To eliminate this possibility, the medial pedicle was designed with a narrower base and no superior attachment, thus permitting a wider arc of rotation. This modification effectively eliminates pedicle rotation complications while maintaining the advantages of the superomedial pedicle.

\section{Physical evaluation and marking.}

1- Assess the upper breast border. This border will not change with the surgery. The distance from the clavicle to the upper breast border will determine whether the patient is "high-breasted" or "low-breasted"

2. Assess the level of the inframammary fold. The fold level is quite variable from patient to patient. The fold can be raised to some degree with this procedure but an aggressive attempt to raise the fold will also increase the revision rate.

3. Assess the lateral breast border. If the breast is quite wide the parenchyma laterally will need to be excised and the breast coned in order to narrow the breast base.

4. Assess the amount of upper pole fullness. Some patients have unrealistic expectations 1028 about what surgeons can achieve - and sometimes the surgeons do as well. The amount of upper pole fullness can be rarely increased without the use of exogenous tissue such as an implant or fat injections.

5. Design the new nipple position relative to the upper breast border. The ideal nipple position should be determined preoperatively with the patient standing. For "C" cup brassiere the new nipple should be about $10 \mathrm{~cm}$ below the upper breast border.

6. Use the Wise pattern for determination of final breast shape. The Wise pattern comes from a brassiere pattern and is not just about the keyhole design. The whole pattern is ideal for determining what should be left behind to get a good final shape. All tissue beyond the Wise pattern should be removed.

7. Close the breast pillars without undue tension. The tissue beyond the Wise pattern should be excised. The breast tissue should be excised directly and any fat beyond the breast tissue can be either directly excised or removed by liposuction. The pillars should be closed without tension. Neither the breast tissue nor the skin should be closed under tension or complications will increase and the shape will relapse. 


\section{Technical steps}

\section{Marking}

1. New nipple position: the key to marking is the upper breast border and evaluating the breast foot print on the chest wall. The upper breast border is the junction between the breast and the upper chest wall. It lies just below the pre-axillary fullness and the indentation below the pre-axillary fullness can be marked and came medially. The breast meridian is then marked. It is not drawn through the existing nipple but drawn where the ideal nipple position should be. The new nipple position should then be placed on the new breast meridian about 8$10 \mathrm{~cm}$ below the upper breast border. This often corresponds with the level of the inframammary fold.

2. Areolar opening: The top of the areola is then marked $2 \mathrm{~cm}$ above the new nipple position. The new areolar opening is drawn so that it will be a circle when it is closed. A good pattern is to use a large paper clip as a template. A large paper clip is $16 \mathrm{~cm}$ in length. This matches a $5 \mathrm{~cm}$ diameter areola there is no need to make the opening a "mosque" shape.

3. Skin resection pattern the vertical limbs of a Wise pattern or keyhole opening are the same for a vertical design. Instead of extending the vertical limbs laterally and medially in an anchor pattern, the two vertical lines are joined together about 2-4 $\mathrm{cm}$ above the inframammary fold. The skin can then be pinched to make sure that enough skin is being left behind. It is important to make the lower portion of the skin resection pattern curved in a "U" shape rather than in a "V" otherwise there will be too much skin excess.

4- Pedicle design. A medial or superomedial pedicle can be designed. The easiest design to inset is one where the base of the pedicle is designed so that one half is in the areolar opening and one half is on the vertical limb.

\section{Operative technique}

A modified wise pattern is delineated on the breast with the patient standing (Fig. 4). The new nipple position is marked at the level of the inframammary fold along the breast meridian. The vertical limbs of the wise pattern are $8 \mathrm{~cm}$ in length. In the operating room with the patient supine, the areolar diameter is marked at $4.2 \mathrm{~cm}$. the medial pedicle is defined with the base of the pedicle oriented medially, such that onethird of the total base width is along the medial vertical limb and two-thirds of the width is along the medial horizontal limb (Fig.4) mean base width of the medial 
pedicle was $9.4 \mathrm{~cm}$. (range, 6 to $1 \mathrm{lcm}$ ), and mean distance from the base to nipple was $14.8 \mathrm{~cm}$ (range, 10 to $19 \mathrm{~cm}$ ). The distal aspect of the medial pedicle is delineated with a I-cm margin around the nipple-areola complex to preserve the vascular plexus.

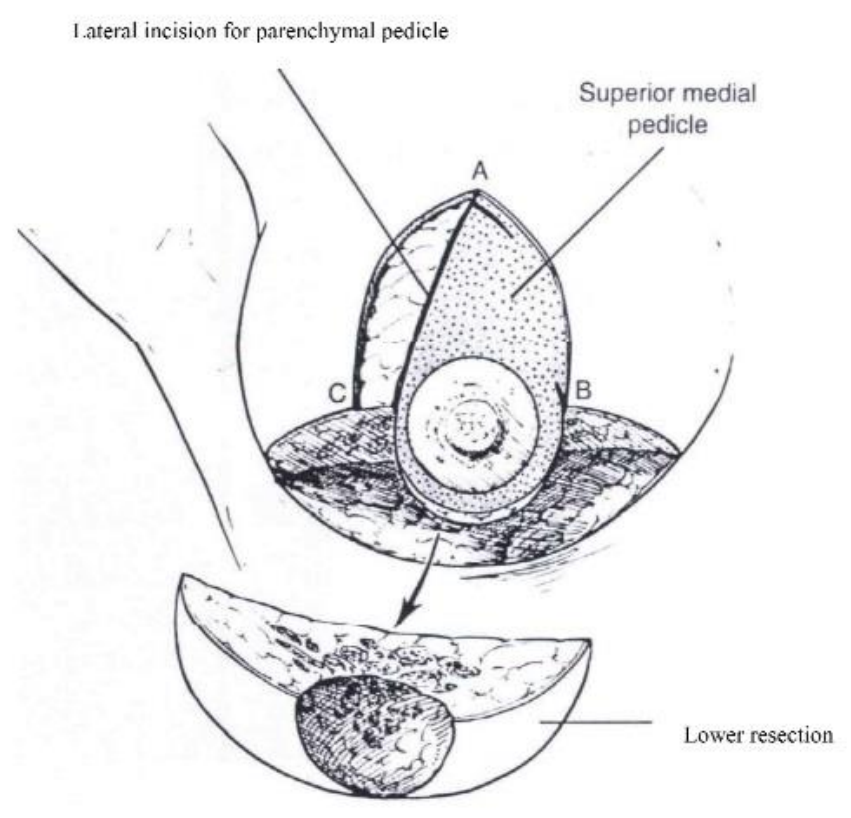

Fig. (4) The dominant internal mammary perforating vessels to the breast and nipple-areola complex. [12]

The incisions are not infiltrated because the veins can be damaged. Infiltration with xylocaine and adrenalin is used for the areas (inferior breast, pre-axillary fullness and lateral chest wall) that will be treated with liposuction. If a patient is overweight a tumescent type of infiltration will be used. The breast itself is not infiltrated.

1- Creation of the pedicle. (fig.5) the pedicle is de-epithelialized leaving a cuff of dermis around the areola. The pedicle is created as a full thickness pedicle. The blood supply starts deep medially as it comes around the sternum from the internal mammary system. Because it then proceeds superficially as it approaches the areola the pedicle can be dermal or dermoglandular. A full thickness pedicle however, will have better sensation and better breast feeding potential. 


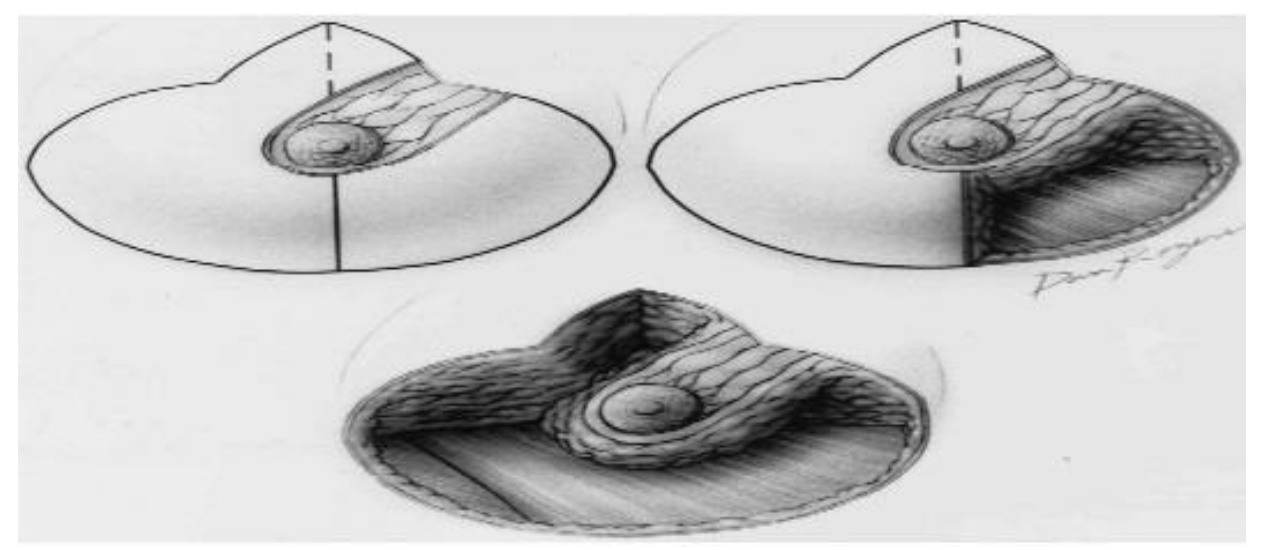

Fig. (5). (Above, left) The de-epithelialized medial pedicle. (Above, right) Medial dermoglandular quadrant resection. (Below) Remaining dermoglandular segments are excised [12].

2 Parenchymal resection the parenchyma is then resected en bloc by removing the tissue around the pedicle. The excision is carried straight down laterally to create the lateral pillar leaving it about $1-2 \mathrm{~cm}$ thick. The lateral excision is then beveled outward to remove breast tissue deep to the lateral flap. It is difficult to remove enough breast tissue with this technique and under resection is a frequent complaint. The parenchyma is then beveled out inferiorly and medially as well as laterally. The best way to remove tissue is to visualize leaving a Wise pattern of tissue behind and to remove all the parenchyma but not the skin - below the Wise pattern. This parenchyma can be directly excised and then tailored out by liposuction. It is best to leave tissue over the pectoralis muscle to 1031 avoid bleeding and to preserve the sensory nerves that pass just above the pectoralis fascia.

3 Closure of the pillars (fig 6) it is easiest to begin by closing the base of the areolar opening with an absorbable suture such as 30 Monocryl. The pedicle can then be inset into place and the inferior border of the medial pedicle then becomes the medial pillar. The whole base of the pedicle rotates into position and this gives an elegant curve to the lower pole of the breast. The pillars correspond to the vertical limbs of the Wise pattern and they are best left at about $7 \mathrm{~cm}$ in a normal breast reduction. The pillars start usually about half way up the skin opening not at either the inferior aspect of the skin 
opening or at the inframammary fold. Again, visualizing the Wise pattern for what is left behind will help visualize the ideal pillar design. The pillars are brought together without tension using about three sutures not much more than a centimeter or so deep to the skin surface. Large deep sutures are unnecessary - the pillars only need to be held together for a few weeks until they are healed together. There is no need to suture the breast tissue or the pillars up onto pectoralis fascia. Trifurcation suture dermal pedicle flap rotated pedicle flap.

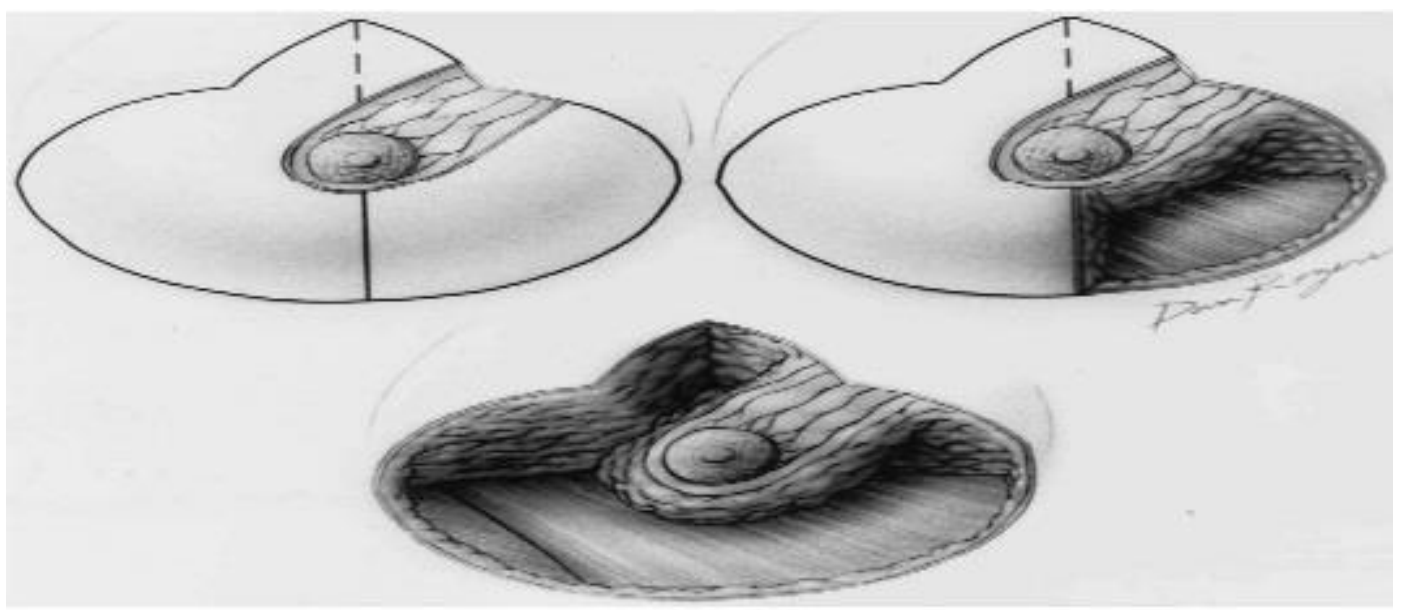

Fig. 6 (A) Trifurcation suture placement. (B) Medial dermal pedicle rotates superiorly. (C) Medial dermal pedicle positioned and suture ligated [12]

4 Closure of the deep dermis. The dermis is then closed with deep interrupted 3- 0 Monocryl sutures. Only enough sutures are needed to achieve dermal to dermal apposition. Too many sutures will interfere with blood supply. Closure of the dermis allows the surgeon to visualize the Wise pattern and to better be able to determine where to perform liposuction. There is no need to suture dermis up onto the breast tissue. Suturing the lower end of the skin to the chest wall will only delay resolution. It will tuck in quite quickly as the weeks pass after surgery.

5 skin closure the areola is closed with some interrupted sutures in the deep dermis and then a subcuticular suture. If the areola is not a complete circle some excess skin can be removed to create a circle prior to closure. The vertical skin is closed with a subcuticular suture that is not pulled tightly. Multiple deep bites will damage blood supply. Pleating or gathering the vertical incision is not only unnecessary, but it can 
cause delayed healing by constricting blood supply and it delays resolution of the final result. This vertical length will stretch back out if it is gathered.

\section{Postoperative care}

Drains are used for 2-4 days. Paper tape is applied to the incisions and left in place for three to four weeks. Patients shower the next day and just pat the tape dry. Bras are used just to hold the bandages in place and to give the patients a sense of support. Patients are allowed to change any form of garment they wish. Patients are not restricted in activities and return to work is usually $2-3$ weeks. The final result of any procedure cannot be properly assessed until a full year has passed. The result at one year after a medial pedicle vertical breast reduction varies little after the first year.

\section{Result}

Clinical outcome measures significantly improved after surgery. Preoperatively there were 20 patients suffering from macromastia. Postoperatively they were all satisfied with the results with only 2 patients suffered from complications 1 with wound dehiscence and 1 with nipple and areola necrosis. 4 patients had secondary surgery 2 of them had liposuction of lateral bulge, 1 patients had revision of scar and 1 patient had excision of dog ear. 
Table (1): Combined results table

\begin{tabular}{|c|c|c|c|c|c|c|c|c|c|c|c|c|}
\hline $\begin{array}{l}\text { Case } \\
\text { num. }\end{array}$ & Age & $\begin{array}{c}\text { Marital } \\
\text { status }\end{array}$ & Parity & $\begin{array}{l}\text { Degree of } \\
\text { hypertrophy }\end{array}$ & $\begin{array}{l}\text { Degree } \\
\text { of ptosis }\end{array}$ & \multicolumn{2}{|c|}{$\begin{array}{l}\text { Amount } \\
\text { removed } \\
\text { (in gm) }\end{array}$} & $\begin{array}{l}\text { Length } \\
\text { from } \\
\text { SSN to } \\
\text { NAC }\end{array}$ & \multicolumn{2}{|c|}{$\begin{array}{l}\text { Distance } \\
\text { of nipple } \\
\text { elevation }\end{array}$} & $\begin{array}{c}\text { Patient } \\
\text { satisfaction }\end{array}$ & $\begin{array}{l}\text { Doctor's } \\
\text { evaluation }\end{array}$ \\
\hline 1 & 27 & $\mathrm{M}$ & Multipara & Moderate & Moderate & 500 & 600 & 32 & 9 & 9 & Yes & - \\
\hline 2 & 23 & $\mathrm{~S}$ & Nullipara & Major & Severe & 1000 & 1100 & 40 & 17 & 18 & Yes & \\
\hline 3 & 34 & M & Multipara & Major & Severe & 900 & 870 & 41 & 18 & 16 & $\begin{array}{l}\text { Uncomfort } \\
\text { shape }\end{array}$ & $\begin{array}{c}\text { Partial NAC } \\
\text { necrosis }\end{array}$ \\
\hline 4 & 33 & $\mathrm{M}$ & Multipara & Moderate & Severe & 650 & 670 & 38 & 14 & 13 & Yes & - \\
\hline 5 & 27 & $\mathrm{M}$ & Multipara & Mild & Moderate & 465 & 480 & 30 & 7 & 8 & Yes & - \\
\hline 6 & 25 & $\mathrm{M}$ & Multipara & Major & Severe & 1380 & 1470 & 38 & 15 & 15 & Yes & - \\
\hline 7 & 19 & $\mathrm{~S}$ & Virgin & Major & Severe & 1180 & 1150 & 35 & 15 & 14 & Yes & - \\
\hline 8 & 35 & $\mathrm{M}$ & Multipara & Major & Sever & 1230 & 1250 & 36 & 14 & 15 & Yes & - \\
\hline 9 & 45 & $\mathrm{M}$ & Multipara & Major & Sever & 1400 & 1420 & 37 & 13 & 14 & Big size & - \\
\hline 10 & 26 & M & Nullipara & Moderate & Moderate & 850 & 860 & 32 & 8 & 9 & Yes & $\begin{array}{l}\text { Wound } \\
\text { dehesince }\end{array}$ \\
\hline 11 & 28 & $0 \mathrm{M}$ & Nullipara & Major & Severe & 1650 & 1640 & 39 & 16 & 15 & $\begin{array}{l}\text { Uncomfort } \\
\text { shape }\end{array}$ & - \\
\hline 12 & 43 & $\mathrm{M}$ & Multipara & Major & Severe & 1340 & 1380 & 36 & 13 & 12 & Yes & - \\
\hline 13 & 33 & $\mathrm{M}$ & Multipara & Major & Severe & 1200 & 1200 & 36 & 13 & 13 & Yes & - \\
\hline 14 & 20 & $\mathrm{~S}$ & Virgin & Mild & Moderate & 350 & 330 & 28 & 7 & 7 & Yes & - \\
\hline 15 & 26 & $\mathrm{M}$ & Nullipara & Moderate & Moderate & 590 & 580 & 31 & 8 & 8 & Breast Pain & -- \\
\hline 16 & 33 & $\mathrm{M}$ & Multipara & Moderate & Severe & 870 & 900 & 33 & 10 & 10 & Yes & - \\
\hline 17 & 39 & $\mathrm{M}$ & Multipara & Major & Severe & 1300 & 1300 & 36 & 13 & 12 & Yes & - \\
\hline 18 & 37 & $\mathrm{M}$ & Multipara & Major & Sever & 1540 & 1570 & 38 & 15 & 13 & Poor Shape & - \\
\hline 19 & 30 & $\mathrm{M}$ & Nulipara & Mild & Moderate & 610 & 620 & 34 & 10 & 11 & Yes & - \\
\hline 20 & 44 & $\mathrm{M}$ & Multipara & Major & Severe & 1045 & 1090 & 33 & 11 & 11 & Yes & -- \\
\hline
\end{tabular}

\section{Discussion}

Multiplicity of techniques of breast reduction indicates that no technique is perfect, and no single technique suits all cases. Criticism of procedures always includes the loss of long term projection, quality and length of the scars, development of boxing and bottoming out. Breast hypertrophy has been and will always be a challenge to breast surgeons, who are always trying to address the problem and look for perfection.

The goals of breast reduction are to reduce the volume while achieving an aesthetically pleasing shape and maintaining breast functions and N/A sensations.

It was mentioned [4] that any operation on the female breast is to be considered an aesthetic procedure, not only augmentation 
and mastopexy, but also reduction and reconstruction. Body image and selfconfidence should be restored, and the appearance of "normal" breast should be enhanced; the goals are the same for any aesthetic procedure.

Although patient perception is that plastic surgery means no visible scars, in reality this is not possible, particularly in breast reduction. Rather our goals should be to keep the scars minimal in length and inconspicuous, as possible as we achieve enhanced shape.

Criticism of the classic procedure based on the Wise pattern resulted from the problem of bottoming out and bad scaring in the long term. While surgeons in the United States focused on the pedicle variations within the confines of the Wise pattern, the European and South American plastic surgeons began aggressively exploring short scar alterative.

The aim of this study is to emphasize the versatility of the medial pedicle technique in all types and degrees of breast hypertrophy especially large size regarding the aesthetic and functional outcome, complications, revision rates, long term results, and overall patient satisfaction.

Selection of the skin resection pattern was based on Bostwick, 2000 [9] recommendations in which the vertical technique was chosen for smaller breast reductions requiring minimal nipple elevation, while those with larger breast reductions requiring more nipple elevation underwent inverted- T scar technique.

Assessment of postoperative aesthetic outcome included shape, size, symmetry and scars.

Vertical approach was found to eliminate the problem of boxy shape, avoid the problem of chasing lateral and medial dog ears as vector of pull is horizontal. It also narrows breast base giving more projection that lasts longer even with repeated pregnancies, this is also what Hall-Findlay, 2005 found in her patients. In the current study, poor shape was recorded in 2 cases $(10 \%)$ of the inverted-T group, and none of the vertical group.

Asymmetry was encountered in 2 patients $(10 \%)$ and was found to occur in those whom breasts were asymmetrical to start with. Davis, 1996 reported an incidence of $8 \%$.

2 cases (10\%) scar hypertrophy and pigmentation, all basically were bad scar formers. In agreement with Hall-Findlay, 2005 those patients should be convinced to try the vertical approach to limit scarring. 
Another series by Davis, 1996 reported an incidence of $18 \%$.

In our closure we followed what Lockwood, 1999 [11] stated that suturing the superficial facial layer provides minimal tension skin repair, which should result in more predictable, finer scaring with reduced risk of scar hypertrophy.

In the present study, none of our patients developed scar widening and one patient (5\%) developed scar puckering. These two patients were found to be of the older age group, multipara, with massive inelastic skin excess which is loosely adherent to parenchyma.

Scar revision was done for one of them 6 months later as she was not patient enough to wait for spontaneous resolution.

In an attempt to refine the aesthetics of the scar, the lower end of vertical skin excision should be about 2, 4 or $6 \mathrm{~cm}$ above IMP (according to size of breast). This is important not only because IMF tends to rise with vertical approach but also because of the ellipse effect: the scar becomes longer in a vertical direction when the ellipse is closed. This is in agreement with a study done in 2005 [14] and disagreement with another done in $\mathbf{2 0 0 0}$ [9] who occasionally extended the scar 2-3 cm below IMF depending on upward migration of the scar.

To avoid the scar from crossing the IMF either the whole scar, or only the lower part of the scar was puckered. The inferior point of the scar may be also anchored to the created new IMF. This has the advantage of hiding the crumpled part of the scar allowing the breast to hang over it, but the disadvantage of preventing the IMF from further upward migration. In 2 cases as well, where the vertical scar exceeded $8 \mathrm{~cm}$, it was converted into short inverted- $\mathrm{T}$ scar. This eliminated excess skin, avoided extensive puckering or vertical scar crossing IMF, and gave a better immediate and late postoperative result as the short horizontal scar is inconspicuous and accepted.

It was believed that puckering is less a problem of excess skin than an excess subcutaneous tissue [14]. It was mentioned that removal of excess fat through a small vertical incision short of crossing the IMF is the proper solution than to do horizontal skin excision that is difficult to locate and then chase dog ears horizontally [14].

Assessment of functional outcome included that of N/ A sensation, lactation and symptom relief 
N/ A sensations were assessed 3 and 6 months postoperatively in the way mentioned before, taking into consideration that 2 patients $(10 \%)$ had preoperative impaired sensation. this goes well with what Jones, 2006 mentioned that the larger the breast, the more likely a patient is to start experiencing reduction in sensitivity preoperatively, possibly owing to the effects of extreme traction on cutaneous nerves by the weight of the breast. In general vertical group patients had better postoperative sensations than inverted- $T$ group. In fact post-operative nipple and areola sensations and lactation is rather related to the amount of resection and the pedicle used than the skin resection pattern.

So, more extensive resections, and the use of thin superior dermal pedicle to facilitate in setting, both lead to poor sensation. Jones, 2006 also mentioned that the more radical the reduction, the more likely a patient suffers long term postoperative numbness of the nipples. He also mentioned that larger breasts take longer to recover sensations than smaller ones. None of our patients went into lactation during the period of the study.

Postoperative complications were few and slightly more common with the inverted- T technique. This goes well with what was stated that vertical scar technique has more 1037 predictable results and fewer complications than the standard inverted- $\mathrm{T}$ technique if it is well executed [15].

In our study only one patient had partial NAC superficial necrosis that healed with repeated dressings while no other NAC necrosis were reported because of the rich vascularity of the medial pedicle in comparison to the superior long pedicle.

No seroma was reported because we left the drains for long period about I week. This is comparable to the study which mentioned an incidence of $1-5 \%$ [15].

Partial wound dehiscence developed in I breast $(2.5 \%)$. In the inverted- $\mathrm{T}$ group it occurred in the $\mathrm{T}$ junction, the wound healed without surgical intervention.

In our study no medial flap undermining was done, only in contrast to what a study advised not to undermine the tips of the medial and lateral flaps so as to maintain good vascularity to the tissues, and avoid delayed wound healing or skin flap necrosis [5].

Approach the resultant breast shape and scar are superior to wise pattern technique. A similar study was done on 153 patients [16]. It was concluded that the rate of complications is comparable, the vertical approach, being with shorter scars and belier 
long term projection, is justified to remain the standard technique.

Both techniques were compared in 105 women. They found no significant difference in aesthetic outcome. Patients with vertical technique were more satisfied with the operation but required higher revision rates compared with those who had inverted- T technique [17].

Recently breast reduction has been divided arbitrarily into long and short scar techniques. Often the Wise pattern is used to describe the inverted- $\mathrm{T}$ inferior pedicle technique. Care must be taken to separate the skin resection pattern from the pedicle design. Wise described a skin resection pattern .1ts not reasonable to compare one skin resection pattern using one pedicle with another skin resection pattern using a different pedicle.

As regard the parenchyma resection pattern and pedicle used: Although the inferior pedicle technique provided good functional results, vascular safety of NAC, good sensations, and possible lactation, the boxy shape, lateral and medial dog ears was an issue that could not be always solved. The development of pseudoptosis or bottoming out with time was believed to be an inevitable consequence of gravity acting on skin [4].

The wise pattern (or lets name it the inverted- $\mathrm{T}$ skin resection pattern) relied on skin brassiere to maintain the shape. This led to the too familiar wide, non-projecting, bottomed out appearance. Now we do what's called' shape and drape'. That's to reduce breast parenchyma, shape the breast, and then manage the skin excess [14].

The evolution of vertical scar reduction mammoplasty markedly reduced scars, narrowed the breast and improved the long term results. However this technique gives its best results when properly selected and properly done. There are still other patients that benefit more from the classic inverted$\mathrm{T}$ scar technique.

In 2006 [5] it was mentioned how far breast surgeons went for vertical reduction.

In 1999 [18], the technique with nipple to stemal notch distance up to $38 \mathrm{~cm}$. was used Also in 1999 [19] this was used safely in resections up to $1000 \mathrm{gm}$, but it was also recommended using other techniques in higher resections.

Some other study done in 1999 [20] have performed 2000gm resections without 
increased incidence of complications or areolar loss.

Others who have applied vertical approach to large-breasted individuals have reported abundant inferior pole skin with only limited postoperative shrinkage, so limited the technique to resections less than $1000 \mathrm{gm}$. It's to be mentioned here that although it may seem that vertical reduction is of limited utility in large volume reductions, it's more likely that these patients with severe hypertrophy are simply more prone to encounter complications, regardless the technique used.

\section{Conclusion:}

This study demonstrates that medial pedicle reduction mammoplasty is a safe surgical option for severe mammary hypertrophy. Current options include amputation mammoplasty with free-nipple graft and the inferior pedicle and bipedicle techniques.

The complications of these techniques, particularly the techniques with long pedicles, have led to a search for alternatives that would preserve the nipple and also permit reduction to a smaller size. Reduction mammoplasty using a medial pedicle is proposed as a procedure that solves these problems. Advantages a medially based pedicle include reliable circulation, preservation of nipple-areola sensation, elimination of nipple-areola hypopigmentation, and enhancement of central breast projection.

The anatomic advantages of a medial pedicle are numerous. The medial pedicle derives its blood supply from the internal mammary artery and its innervation from the intercostal nerves. Studies on the vascular territories of the breast and nipple-areola complex have demonstrated the internal mammary artery to be the dominant blood supply in 70 percent of patients. The studies on the innervation of the nipple-areola complex [21] have demonstrated fine branches from both the anterior (medial) and lateral 4th 5th and 6th intercostal nerves [22].the orientation of the medial pedicle permits inclusion of the dominant vasculature and a portion of the central breast innervation. In addition, the pedicle permits a wider are of rotation, thus providing flexibility in placement and positioning, which minimizes complications.

\section{References}

1. Walton RL and Gonzalez F (1994): The parenchymal pedicle technique for reduction mammoplasty. In: Cohen M: Mastery of plastic and reconstructive surgery. Little, Brown and Company, Boston, New York, Toronto, London, p. 2126. 
2. Plast. Reconstr. Surg. 105: 896, 2010.

3. The Division of Plastic Surgery at Johns Hopkins Medical Institutions. Received for publication June 12, 1999; revised July 30, 1999. 896

4. Nahai F (2005): Clinical Decision-Making in Breast Surgery. In: The Art of Aesthetic Surgery, Quality Medical Publishing; pp. 18181825 .

5. Jones G (2006): Breast Reduction. In: Plastic Surgery McCarthy, 2nd ed. Saunders Company, Philadelphia, pp. 539-584.

6. Orlando JC and Guthrie RHJr (1975): The superomedial dermal pedicle for nipple transposition. Br. J. Plast. Surg., 28: 42.

7. Hauben DJ (1985): Experience and refinements with Superomedial dermal pedicle for nipple-areola transposition in reduction mammoplasty. Aesth. Plast. Surg., 8: 189.

8. Finger RE, Vasques B, Drew GS and Given KS (1989): Superomedial pedicle technique of reduction mammoplasty. Plast. Reconst. surg., 83: 471

9. Bostwick J/// (2000): Reduction Mammoplasty. In: Plastic and Reconstructive Breast Surgery, 2nd ed. St. Louis, Missouri, Quality Medical Publishing, pp. 372-497.

10. Muller FE (1974): Late results of Strombeck's mammoplasty. A follow-up study of 100 patients. Plast. Reconst. Surg., 54: 664 .
11. Orlando JC and Guthrie RHJr (1990): The superomedial dermal pedicle for nipple transposition. Br. J. Plast. Surg., 28: 42.

12. Nahabedian, Maurice Y. ; McGibbon, Bemard M.; Manson, Paul N. Plastic \& Reconstructive Surgery. March 2000.

13. Lockwood, T (1999): Reduction mammoplasty and mastopexy with superficial fascial system suspension. Plast. Reconst. Surg., 103:1411

14. Hall-Firdlay EJ (2005): Reduction Mammoplasty. In: The Art of Aesthetic Surgery. Foad Nahai, Quality Medical Publishing, pp. 19532043.

15. Boehm K and Nahai F (2006): Vertical Reduction. In: Plastic Surgery McCarthy, 2nd ed. Saunders Company, Philadelphia, pp. 585599.

16. Beer GM, Morgenthaler W, Spicher 1, Meyer VB (2004): Modifications in vertical scar breast reduction. Br. J. Plast. Surg., 54: 341-347.

17. Korchin L, Cruz-Korchin N (2003): Vertical versus wise pattern breast reduction. Plast. Reconst. surg., 1 12: 15731581

18. Lassus C (1996): A 30-year experience with vertical mammoplasty. Plast. Reconst. surg., 97: 373-380.

19. Lejour M (1999): Vertical mammoplasty: update and appraisal of late results. Plast. Reconst. surg., 104: 771 
20. Nahai and Lacotte, Discussion an update on vertical mammoplasty. PRS, 104: 22992302.

21. Plamer. J. H. , and Taylor, G. 1. The vascular territories of the anterior chest wall. Br. J. Plast. surg. 39: 28'7, 1986.
22. Sarhadi, N.S., Dunn.J.S. Lee, F.D., and Soutar D.S An anatomical study of the nerve supply of the breast, including the nipple and areola. B r. J. Plast. Suro. 49; 156, 1996.

To cite this article: Hany Salah, Mostafa Bayoumi, Ayman M. Abdelmufeed, Mohamed Y. Farid. Medial Pedicle Reduction Mammoplasty in Macromastia. BMFJ 2021; 38(3): 1019-1041. DOI: 10.21608/bmfj.2021.17254.1070 